\title{
Utilization pattern of health care services at a peripheral health care facility of Nepal
}

\author{
B Bista, D Rai, RA Sagtani, SS Budhathoki \\ School of Public Health and Community Medicine, BPKIHS
}

\begin{abstract}
Background: In Nepal, basic health care services at the grass root level are delivered by Subhealth Posts (SHPs) and Health Posts (HPs). The basic aim of these institutions is to deliver essential health care services. In accordance of the Alma Ata declaration on primary health care (PHC) Government of Nepal (GoN) adopted free health care policy on 2006 A.D. to make basic health care services accessible, affordable and available. Thus, SHPs and HPs offer free of cost services to every Nepali citizen. The current study was conducted with the aim of finding utilization pattern of health care services in a peripheral level institution of Sunsari District. Methods: A descriptive study was carried out in Panchkanaya, a sub- health post of Sunsari district utilizing both qualitative and quantitative methods. Data was collected through face to face structured interviews with fifty patients and an in depth interview with in charge of the sub health post. Furthermore, secondary data from records of Health Management Information System (HMIS) of Nepal were also utilized. Results: Out of total patients, most of them were female (67.4\%) and majority of patients were from higher age group (>50years). Most of the patients were involved with agriculture as their occupation. Regarding accessibility of health services, most of the respondents could reach sub- health post via walking within 15 minutes. Fifty percent of the patients were satisfied with services provided by the sub-health post. From qualitative aspect, health careservices were under utilized by the people from the northern side of VDC due to inappropriate location of the health post. Conclusion: Health care services were easily accessible although only fifty percent of patients were satisfied by the services.
\end{abstract}

Keyword: Free health care services, sub health posts (SHPs), utilization

\footnotetext{
Address for correspondence

Dr. Bihungam Bista

School of Public Health \& Community Medicine

B.P. Koirala Institute of Health Sciences, Dharan

E-mail: bistabihungum@gmail.com
} 


\section{Introduction}

Health services are the services provided by health care personnel for the purpose of promoting, maintaining or restoring health. In Nepal, with the goal of providing quality health services to all Nepalese people and to take up the responsibility of promotion, regulation and management of health care institutions, the department of health services under Ministry of health and population (MOHP) was established in $1953^{1}$.

Nepal's National health policy of 1991 stated that health care services would be expanded throughout the country including rural areas ${ }^{2}$. In October 2007, the Government of Nepal (GoN) declared free health services at HPs and SHPs with the aim of increasing access and utilization of basic health services, particularly by poor and excluded groups ${ }^{3-4}$. This policy was envisioned to mitigate the financial barriers in seeking care, provide relief to poor families, promote the utilization of essential health care services, and, ultimately, contribute to improve the health status of the population ${ }^{5}$.

The current study was designed to find out utilization pattern of health care services in a peripheral level health care institution of Sunsari district.

\section{Methods}

A descriptive study was carried out using both quantitative and qualitative methods over a period of one month through subsequent visits to the Panchkanaya subhealth post of Sunsari district. Data was collected with the help of a pretested structured questionnaire through face to face interviews with the patients attending the subhealth post. Furthermore, qualitative information was extracted through an in depth interview with in charge of the sub-health post. The patients who were not mentally fit and below age of fifteen years were not included in the study. The study was conducted by using non - probability quota sampling and the sub health post was selected according to convenience of the researcher. Information was collected from all the clients visiting OPD section of sub-health post on the particular day of data collection. The data was coded, entered and analyzed through SPSS version 15.0. Ethical approval of the study was taken from ethical committee of BPKIHS, and informed consent was taken from all the study respondents.

\section{Results}

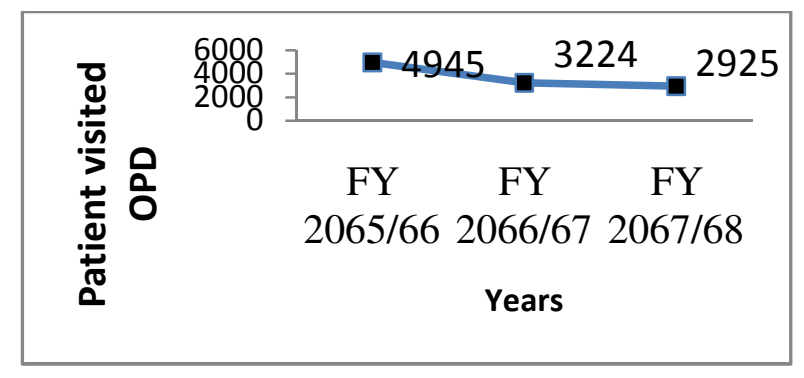

Fig.1: Number of patients attending OPD of Panchkanya sub health post 
Figure 1 shows the trend of utilization of services in last three years, and during year 65/66 large number of patients visited SubHealth post. With time, health services utilization from sub-health post has been decreasing. It might be due to the awareness regarding quality health services provision from other institutions (e.g BPKIHS, Clinic). It might also be due to health personnel related issues or other health related problems development which couldn't be solved from sub- health post level. So, in this aspect further more study is needed.

\section{Sex distribution of the participants.}

In the current study, the total number of patients who participated was fifty. Among total participant $67.4 \%$ were females and 32.6 $\%$ were males.

\section{Age group}

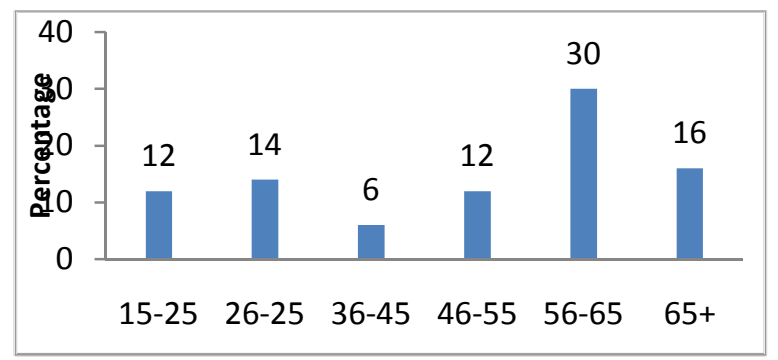

Fig. 2: Age distribution of study respondents

Among the total respondents, $40.2 \%$ were from the youth group i.e. 15-25 years and about $75 \%$ were from the productive age group i.e. $15-45$ years as shown in fig. 2

\section{Ethnic distribution}

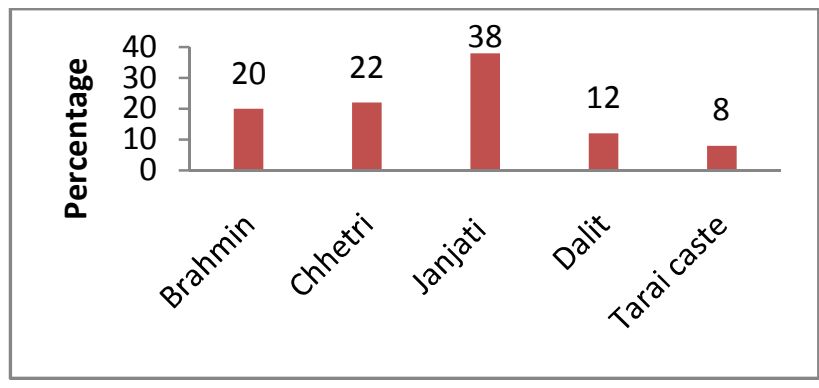

Fig. 3: Ethnic distribution of study participants

Among total 50 patients, most of the patient belongs to the Janjati ethnicity which was followed by Chhetri, Brahmin, Dalit and Tarai caste (Fig.3)

\section{Accessibility}

Almost 67 percentages of the health service consumers could reach the sub health post in less than 15 minutes and 26 percentages were from the distance which takes 15-30 min to reach the health facility for seeking health services.

\section{Results from the in depth interview}

The in-charge of Sub-health post reported that majority of the service consumers were female and children, old age people, and marginalized group which is also target of Government of Nepal. Furthermore, most of the services were utilized by those who were nearby with sub-Health post and people away from sub-health post were either going to Dharan municipality nearby clinic or BP Koirala Institute of Health Sciences. Patients 
from the northern part of Panchkanya village development committee (VDC) were not using services due to inappropriate location of the sub-health post. He also mentioned that acute respiratory infections and skin diseases were the most common diseases at the Panchkanya VDC, which is similar to Nepalese national scenario. Furthermore, he stressed that patients with signs and symptoms of non-communicable diseases were increasing significantly in the recent times. Regarding availability of drugs at subhealth post, he stated that all the essential drugs enlisted as free drugs by GoN were adequately available at the sub health post except iron tablets. The distribution of iron tablets was stopped by government of Nepal due to some technical problems.

\section{Conclusion}

Health care services were easily accessible to the incoming patients however only half of them were satisfied by the services. The services were utilized by the target group of Nepal's free health care policy. Major issues faced by sub-health post were inappropriateness of location of sub-health post and inadequate supply of iron tablets.

\section{References}

1. A Summary of the Free Cost of Health Care in Nepal. May 2008. Available on: http://www.hsrsp.org/pdf/Technical_Brie f_1_-Costing_Summary.pdf. (Retrived on: 7th March, 2013).

2. National health policy 1991.

3. Assessing the Implementation of Nepal's Free Health Care Policy. Ministry of Health and Population, Nepal, 2009. Available on: http://www.hsrsp.org/pdf/3rd_Round_Fa cility_Survey_Report_FINAL.pdf. (Retrieved on: 2nd November, 2012).

4. Briefing Paper on Essential Health Care Services (EHCS) in Nepal. Available on: http://www.ridanepal.org/downloaded/E HCS\%20briefing\%20paper.pdf.(Retrive d on: 2th November, 2012).

5. Health Sector Gender Equality and Inclusion Strategy. Ministry of Health and Population, Nepal, 2009. http://www.ministerialleadership.org/site s/default/files/resources_and_tools/Heal th_Sector_GESI_Strategy_Dec_25_FIN $A L \_(2) . p d f$. On retrived on: 1th December,2012). 